
\title{
25 Research Square \\ Pilot Remote Clinical Communication Skill Session During COVID-19 Pandemic: Medical Education in New Normal
}

Gajarishiyan Rasalingam ( $\nabla$ g.rasalingam@sms.ed.ac.uk)

University of Aberdeen https://orcid.org/0000-0002-4358-9105

\section{Research Article}

Keywords: Clinical Communication Skills, Medical education, Musculo skeleton disease, Remote session, Online learning

Posted Date: December 17th, 2021

DOI: https://doi.org/10.21203/rs.3.rs-1111671/v1

License: (c) (1) This work is licensed under a Creative Commons Attribution 4.0 International License. Read Full License 


\section{Abstract}

\section{Introduction}

Clinical Communication teaching has relied heavily on face-to-face teaching using Patient Partners. The current situation with COVID-19 has led to lockdown, social isolation and travel difficulty. This leads to challenges in delivering this teaching. The study aim is to pilot a clinical communication teaching session remotely, using a virtual learning environment and video conferencing. This study evaluates the pilot about achieving learning outcomes on Musculo Skeleton disease and experience of student's and patient partner.

\section{Methods}

Mixed qualitative and quantitative data are obtained through an online survey. The thematic framework is used to analyse the qualitative data and the descriptive statistics are used to evaluate the quantitative responses.

\section{Results}

The study provided satisfaction on proceeding this new pilot remote communication session to the routine medical curriculum, with $100 \%$ recommendation by the students. The majority of students had transformed their theoretical knowledge in the Musculo Skeleton disease system to consult with patient partners. The study also finds some gaps such as delays due to internet and device faults, limited time to build rapport with patients, nonverbal expressions are not being conveyed via the screen and difficulties in adapting to new remote sessions in short transition.

\section{Conclusion}

Looking into the future of new normal. Remote clinical communication session worked well during the pilot study. New innovatory methods in delivering remote teaching and more studies on different diseases topics should be implemented to analyse the sustainability and validity of the remote session for continuous delivery in medical education.

\section{Introduction}

Effective clinical communication is essential for delivering efficient quality care and establishing a Doctor-Patient relationships with empathy and compassion. In the UK, teaching and assessment on clinical communication (CC) skills is a central component of the medical school's curriculum ${ }^{1}$ and relied heavily on face to face teaching in universities. The current unprecedented COVID-19 pandemic had existentially challenged in delivering this teaching due to lockdown, safety concerns, universities closure and travel restrictions ${ }^{2}$. There are many studies that had previously evaluated traditional face to face learning but are limited to remote communication skills teaching ${ }^{3}$.To adapt to this new normal during and after the post-COVID-19 situation, the School of Medicine, University of Aberdeen had implemented a 
pilot remote clinical communication session. In this pilot session, we appraise the Musculo skeleton disease (MSD). The main objective of this study is to: evaluate the pilot blended learning on learning outcomes, explore the student and patient-partners experience.

\section{Methods}

For our pilot study, we had recruited total of 66 participants ( 43 second year medical students and 23 patient-partners). On the semester student were taught on the MSD and provided with preparatory learning materials. In the last week of the term, MSD CC session was held for 5 days in 23 separate groups. Each session has one tutor with up to five students and a patient-partner. A session lasts up to one hour, after the end of each session, the medical school administrator had circulated an online "SNAP Survey" to obtain feedback from the student and the patent partners on their experience.

The student survey consists of 43 questions, which is divided into 5 broad domains: general aspects of the remote session, technology status, patient-partners experience, communication and overall suggestions. The survey consists of the Likert scaling method and open-ended questions to capture students' views in each domain. The patient-partners survey is extracted from the validated patient CARE questionnaire. The CARE measure was originally developed by the University of Glasgow to measure doctor-patient consultation and relational empathy ${ }^{4}$. Priory permission is given by the author to use in our study. Additionally, to obtain the students perspective on their patient care, CARE measures questions were modified in a way for the student to self-rate their own consultation, as a part of the student survey. The Standard Survey used in this study is included in Appendix 01 and Appendix 02.

Qualitative responses: To increase qualitative rigour, we used Braun and Clarke's ${ }^{5}$ (2006) thematic analysis, which helped us to orient the data and analyse both student and patient-partner qualitative responses. Each feedback was reviewed by two researchers (GR and NF) independently, opinions are debated and final coding was constructed. We identified the main themes and several subthemes were fixed under them. Quantitative responses: Data is analysed using the R-software (version 3.6.0). The analysis consists of descriptive statistics, frequency, percentage, mean and median. Each participants gave a completed consent before the start of the survey and the medical school curriculum board grand permission for conducting this study.

\section{Result}

All participants respond to the survey. Majority of student's joined the session from the UK and one student from Singapore. From the analysis of our qualitative response, from the student survey 06 themes were identified, with a total number of 12 sub-themes and from patient-partners survey, 03 themes with 07 sub-themes were identified, which is presented in (Table 01). (Table 02) describe the summary and participants thoughts under each theme. 
All students stated that they feel more convenient and comfortable attending the remote session. Some students $(36 \%, n=14)$ encounter technical difficulties during the CC remote session and few students ( $8 \%$, $\mathrm{n}=3$ ) expressed that they are not prepared to undertake the remote consultation. All students agreed: they understood the learning outcomes of the $\mathrm{CC}$ remote session, MSD preparatory learning materials are sufficient to undertake the $\mathrm{CC}$ remote session, content covered are appropriate and the session helped them to transfer their theoretical knowledge of the MSD system to consult with a patient partner. Student's $(95 \%, \mathrm{n}=36)$ felt that they performed a holistic and sensitive approach in exploring the patient perspective of MSD conditions, explaining the possible differential diagnosis ( $87 \%, n=33)$ and negotiating an appropriate management plan. Most students $(96 \%, n=36)$ strongly feel that the discussion time was more beneficial because it had given a loop for understanding the MSD better and stressed more time on discussion. If the student couldn't be able to attend the remote session, they were adequately informed $(97 \%, n=38)$ by the school on an alternative way of achieving the learning outcome. All students remained engaged and had a good rapport with the tutor. Students $(96 \%, n=38)$ felt part of the student community when working with others on this session. All students $(100 \%, n=39)$ agreed that they recommend this remote communication session to other medical students.

The CARE Survey response on empathy measurement is sawn in (Table 03). Which evaluate the patient rating of the student empathy and student self-rating on their consultation with patients.

\section{Conclusion}

Our pilot study reviled that the remote CC skill session saw a favourable student's experience. The study proves high convenient method during this unprecedented pandemic. The Study also manifest the high possibilities in delivering the CC skill teaching via an online platform, as students: obtained their learning outcomes, demonstrated a holistic and sensitive approach to exploring patient perspective; could be able to explain the possible differential diagnoses and negotiate an appropriate management plan. The responses on CARE patient-partners survey on empathy, had also indicate that student could be able to saw positive relationship building approach via the remote session. The study had outline limitation of time, technology and poor internet, difficult in quick rapport building and nonverbal expressions are not being convey are some key gaps identified. This study warrant that, remote clinical communication session can be deliver in replacing the traditional face-to-face method, during this pandemic. The study suggests for more study on the other diseases for CC skills, as result may be significantly vary for other complex diseases on remote teaching. New studies on focusing on refinements in innovatory methods in remote session can result in advancement on this area.

\section{Declarations}

\section{Acknowledgement}

Great thanks to the Medical Education Curriculum Board, School of Medicine, the University of Aberdeen for proving an opportunity to conduct this study. I would like to thank Christine kay, Ching-wa chung, 
Kathrine Gibson smith, Lorraine Hawick and Shraya Allumalla for guiding the study during the analysis stage.

\section{Funding}

The authors did not receive support from any organization for the submitted work.

\section{Conflict of interest}

The authors declare that they have no conflict of interest.

\section{Ethical Approval}

The study was approved by the School of Medicine, University of Aberdeen

\section{References}

1. Brown J. How clinical communication has become a core part of medical education in the UK. Med Educ. 2008;42(3):271-278. doi:10.1111/j.1365-2923.2007.02955.x

2. Alsoufi A, Alsuyihili A, Msherghi Al, et al. Impact of the COVID-19 pandemic on medical education: Medical students' knowledge, attitudes, and practices regarding electronic learning. Published online 2020. doi:10.1371/journal.pone.0242905

3. Dost S, Hossain A, Shehab M, Abdelwahed A, Al-Nusair L. Perceptions of medical students towards online teaching during the COVID-19 pandemic: a national cross-sectional survey of 2721 UK medical students. Published online October 2, 2020. doi:10.1136/bmjopen-2020-042378

4. Mercer SW, Maxwell M, Heaney D, Watt Mercer SW GC. The consultation and relational empathy (CARE) measure: development and preliminary validation and reliability of an empathy-based consultation process measure. Fam Pract. 2004;21(6). doi:10.1093/fampra/cmh621

5. Braun V, Clarke V. Using thematic analysis in psychology. Qual Res Psychol. 2006;3(2):77-101. doi:10.1191/1478088706QP0630A

\section{Tables}

Table 01 Present the themes and sub-themes for the students and patient-partners qualitative responses. 


\begin{tabular}{|c|c|}
\hline Themes & Subthemes \\
\hline \multicolumn{2}{|l|}{ Students Survey } \\
\hline 1. Large versus small group size & \\
\hline \multirow{3}{*}{ 2. Consequences of lack of time } & - Lack of discussion \\
\hline & - Engaging with student's community \\
\hline & $\begin{array}{l}\text { - Accommodating many content in limited } \\
\text { time }\end{array}$ \\
\hline \multirow{2}{*}{$\begin{array}{l}\text { 3. What makes clinical } \\
\text { communication effective }\end{array}$} & - Pre-preparatory lectures \\
\hline & - Helpful discussion part \\
\hline \multirow{2}{*}{$\begin{array}{l}\text { 4. student's expectation on the clinical } \\
\text { session }\end{array}$} & - Increase the frequency of sessions \\
\hline & - Students'suggestions \\
\hline \multirow{3}{*}{ 5. Disrupted learning } & - Late joining \\
\hline & - Audio cut \\
\hline & - Bad connection \\
\hline \multirow{2}{*}{$\begin{array}{l}\text { 6. Building rapport with remote } \\
\text { patients }\end{array}$} & - Difficulties on remote consultation \\
\hline & - Lack of practice for a long time \\
\hline \multicolumn{2}{|l|}{ Patient Partners Survey } \\
\hline \multirow{3}{*}{$\begin{array}{l}\text { 7. What makes the consultation } \\
\text { effective }\end{array}$} & $\begin{array}{l}\text { - Effective and pleasant engagement by the } \\
\text { student }\end{array}$ \\
\hline & $\begin{array}{l}\text { - Resilience amongst students to adapt to new } \\
\text { normal }\end{array}$ \\
\hline & - tele- consultations-new alternative \\
\hline \multirow{2}{*}{$\begin{array}{l}\text { 8. Students' Knowledge on clinical } \\
\text { communication on MSK disease }\end{array}$} & - Student specific gaps \\
\hline & - treatment advice \\
\hline \multirow{2}{*}{ 9. Disruptive Interaction } & $\begin{array}{l}\text { - technical issues due to connectivity and } \\
\text { devices }\end{array}$ \\
\hline & - Ineffective rapport \\
\hline
\end{tabular}


ıble 02: Presents the analysis summary of the qualitative responses on both students id patients-partners under each identified theme.

udents responses

irge versus small group size

1 students had expressed that they were very happy with the group size of 4-5 students, so stated that they felt more comfortable, got a chance to practice and engaging with ich size was much easier.

enjoyed the small group and you feel more comfortable speaking up and that you can " heard when the groups are of this size...."

insequences of lack of time:

Iw students said that due to lack of time, they felt they had limited discussion, hard to iild up a rapport and couldn't practice their consultation. Students expect extra time to st more feedback and have an extensive clinical discussion.

hat makes clinical communication more effective?

e-preparatory lectures, learning material and resources on the MSD, had helped udents to understand the clinical knowledge on MSD, understand the reason behind ıch question being asked to the patient and make a holistic optimistic approach like a al clinician.

udents expectations of the clinical session

crease the frequency of the session. Students had also suggested that more flexibility on e dates, swapping the session with other students and giving advance notice on the ssion will be more helpful, as students experience different challenges or situations in use or living place.

isrupted Learning

sspite all the students agreeing they were provided with adequate information on how deal with the technical difficulties. A common problem among the students encounter a bad internet connection. Internet strength is not sufficient for a group video call, opping of connection within the group, audio and video cut, lagging and some students sed to turn off their video for most of the session to stay connected.

'onnection issues from the tutor and multiple students delayed the session and made it ird to follow at times"

re late joining of the participant affects the learning during the mid of the session and ggested restricting the late joining. Meantime, many students got drop-down and joined due to the poor connection. It is being suggested that giving time to resolve the chnical check before the properly scheduled time, can minimize this issue.

jilding rapport with remote patients

udents expressed that they learned a lot during this first remote consultation session Id had improved their history-taking skills. There was good rapport with the tutors. so, the student felts as a part of the student community when they are working with hers in these remote settings. Some students found it difficult to communicate and innect with the patient over this remote session, they had personally felt that they were it good in history taking and others felt that most nonverbal actions and eye contact are tt being properly conveyed via the screen.

found it hard to connect with the patient over video and therefore didn't feel as though $y$ history taking was as good as it normally is but perhaps it'll be something that comes ith more practice"

itient partners responses

jilding rapport with remote patients

udents were confident; had a pleasant consultation; strong willingness to participate in is remote session; adjusted to the patient's preference; friendly facial expression; open sproach; empathy; excellent ascertaining; concern about the patient satisfaction with eir advice; giving reassurance. 
Iw students faced problems as they began to interact with their patients, but settled ell. The student saws a positive resilient to adapt to the current new normal.

udent's knowledge on clinical communication on MSD diseases

sme students had certain gaps in their knowledge on MSD disease, few had used the rong choice of words in their conversation; included medical terms; few did not obtain oper history, whereas few gave a care plan based on the history gathered by the lleagues.

verall, most of the students had provided a good treatment plan, based on the health inditions and delivered reassurance. Additionally, few had gone the extra mile by commending and providing a treatment plan if things worsen.

\section{isruptive Interaction}

rstly. Technical difficulties and Internet connection are a common problem encountered id most time got wasted on fixing it, suggesting an extra time in the beginning to fix ese issues

?condly, inadequate rapport by few students. Some students found it difficult to tablish a relationship and interact effectively with the patients. Few of them were very Ixious, just went with the flow of the session. It should be also taken into account that, ; each session scenario were split amongst the students in the group, it was challenging $r$ each student to develop a relationship with the patient in the given time.

... student was very nervous about the session I felt, they were just going through the otions, they didn't engage with me as a person, they just wanted facts. No discussion out my work which was a concern or what effect it was having on my life.... 
ible 03: The table represents CARE survey data of the Patient partners and students lf-rating them about the care. (This table questions represent the modified CARE survey r students self-rating, The CARE measure patients-partner attached in Appendix 2)

\section{Questions}

1: Make the patient feel at ease (introducing yourself, being iendly and warm, treating the patient with respect; not sing cold or abrupt)

2: Let the patient tell their story (giving the patient time to lly describe their condition in their own words, not terrupting, rushing or diverting the patient)

3: $\quad$ Demonstrate you were really listening (being able to iy close attention to what the patient is saying, looking at e patient when you are talking)

4: Demonstrate you were interested in the patient as a hole person (asking/knowing relevant details about the itient's life, not treating them as "just a number")

j: Demonstrate that you fully understood the patients incerns (communicating that you have accurately iderstood the patient's concerns and anxieties, not rerlooking or dismissing anything)

j: Show care and compassion (being concerned, innecting on a human level, not being indifferent or letached")

7: Be positive (having a positive approach and attitude, sing honest but not negative about patient's problems)

3: Explain things clearly (fully answering questions, plaining things clearly, providing adequate information, it being vague)

9: Help the patient take control (exploring what they can ) to improve their health, encouraging the patient)

10: Make a plan of action (discussing options, involve them making decisions, taking their views into consideration) he Mean Value is round off to 0.5

\begin{tabular}{|c|c|}
\hline $\begin{array}{c}\text { Patient } \\
\text { Partners on } \\
\text { Students: } \\
\text { Mean } \\
\text { (Status) }\end{array}$ & $\begin{array}{l}\text { Student's } \\
\text { self- } \\
\text { Rating: } \\
\text { Mean } \\
\text { (Status) }\end{array}$ \\
\hline $\begin{array}{c}3 \\
\text { (Good) }\end{array}$ & $\begin{array}{c}3 \\
\text { (Good) }\end{array}$ \\
\hline $\begin{array}{c}3 \\
\text { (Good) }\end{array}$ & $\begin{array}{c}3 \\
\text { (Good) }\end{array}$ \\
\hline $\begin{array}{c}3 \\
\text { (Good) }\end{array}$ & $\begin{array}{c}2 \\
\text { (Fair) }\end{array}$ \\
\hline $\begin{array}{c}3 \\
\text { (Good) }\end{array}$ & $\begin{array}{c}3 \\
\text { (Good) }\end{array}$ \\
\hline $\begin{array}{c}3 \\
\text { (Good) }\end{array}$ & $\begin{array}{c}3 \\
\text { (Good) }\end{array}$ \\
\hline $\begin{array}{c}3 \\
\text { (Good) }\end{array}$ & $\begin{array}{c}2 \\
\text { (Fair) }\end{array}$ \\
\hline $\begin{array}{c}3 \\
\text { (Good) }\end{array}$ & $\begin{array}{c}3 \\
\text { (Good) }\end{array}$ \\
\hline $\begin{array}{c}3 \\
\text { (Good) }\end{array}$ & $\begin{array}{c}3 \\
\text { (Good) }\end{array}$ \\
\hline $\begin{array}{c}3.5^{*} \\
\text { (Excellent) }\end{array}$ & $\begin{array}{c}3 \\
\text { (Good) }\end{array}$ \\
\hline $\begin{array}{c}3 \\
\text { (Good) }\end{array}$ & $\begin{array}{c}4 \\
\text { (Excellent) }\end{array}$ \\
\hline
\end{tabular}

\section{Appendix}

Appendices 1 and 2 are not available with this version 